\title{
SILÊNCIO E VERBALIZAÇÃO: A MATRIZ METAPSICOLÓGICA DE KARL ABRAHAM E ROBERT FLIESS
}

SERGIO GOMES ${ }^{1}$

\section{Sergio Gomes}

${ }^{1}$ Universidade Federal do Rio de Janeiro (UFRJ), Supervisor de Estágio no Instituto de Psicologia, Divisão de Psicologia Aplicada Profa Isabel Adrados (IP/DPA), Rio de Janeiro/ RJ, Brasil. PósDoutorando do Programa de PósGraduação em Psicologia (USP).
RESUMO: O presente artigo objetiva analisar a matriz metapsicológica do silêncio a partir das contribuições teóricas de Karl Abraham e Robert Fliess. Para Abraham, o silêncio é compreendido a partir dos conceitos de erotismo oral, uretral, genital e anal e da influência da libido e das zonas erógenas no desenvolvimento da personalidade e do caráter. Para Robert Fliess, o silêncio é entendido a partir do aparelho da linguagem descrito como uma descarga pulsional regressiva erótica, correspondendo assim a três formas particulares de fechamento esfincterianos: o silêncio erótico-uretral, o silêncio erótico-anal e o silêncio erótico-oral.

Palavras-chaves: silêncio, verbalização, metapsicologia, Karl Abraham, Robert Fliess.

Abstract: Silence and verbalization: a metapsychological matrix of Karl Abraham and Robert Fliess. This article aims to analyze the metapsychological matrix of silence from the theoretical contributions of Karl Abraham and Robert Fliess. To Abraham, silence is understood from the concepts of oral, urethral, genital and anal eroticism and the influence of libido and erogenous zones in the development of personality and character. To Robert Fliess, silence is understood from the language apparatus described as a regressive erotic instinctual discharge, thus corresponding to three particular forms of sphincter closure: the erotic-urethral silence, the erotic-anal silence and erotic oral silence.

Keywords: silence, verbalization, metapsychology, Karl Abraham, Robert Fliess.

DOI - http://dx.doi.org/10.1590/S1516-14982018003009

Todo o conteúdo deste periódico, exceto onde estiver identificado, está licenciado sob uma Licença Creative Commons (cc by 4.0) 
A hipótese segundo a qual a vocalização e a elocução, assim como o erotismo anal, estão estreitamente ligados, não apenas de maneira ocasional e excepcional, mas sistematicamente. O provérbio 'o silêncio é de ouro' poderia ser exatamente a confirmação desta hipótese pela psicologia popular.

Sándor Ferenczi, O silêncio é de ouro.

\section{INTRODUÇÃO}

Ao revisar a literatura psicanalítica, podemos observar dois momentos históricos em que o silêncio foi tema de interesse por parte dos analistas. O primeiro refere-se ao período compreendido entre 1927 e 1935, no qual houve três congressos abordando o silêncio. Dois deles realizados pela Sociedade Psicanalítica de Viena, respectivamente em 1927 e em 1935, e outro pela Sociedade Psicanalítica da Hungria, em 1934. Em todos eles, a discussão girava em torno das contribuições teóricas de Freud e seus contemporâneos. O outro momento refere-se a um colóquio realizado pela Associação Americana de Psicanálise, realizado em 1958, cujos trabalhos foram todos publicados em uma revista especial, em 1961 (BARANDE, 1963).

Entretanto, quando algum comentário sobre o silêncio na análise era encontrado na literatura, mais uma vez, o foco centrava-se nos efeitos do silêncio do paciente a partir do trabalho do analista. O silêncio do paciente foi sempre interpretado pela psicanálise clássica como uma organização de defesas superegoicas com possíveis reações (contratransferenciais) provocadas no analista, ou como dificuldades no manejo da técnica.

O silêncio na clínica psicanalítica seguiu seus próprios caminhos, na medida em que os analistas tiveram que se defrontar com uma pluralidade de sentidos. Esses sentidos devem ser pensados sob dois prismas bastante nítidos: 0 silêncio do analista - a partir da sua escuta profunda e do manejo do enquadre clínico, que potencializava as tensões e as angústias do paciente para que ele comunicasse os conteúdos inconscientes por meio da verbalização -, e o silêncio do analisando - observado como sendo uma resistência à figura do analista a partir da sustentação do enquadre clínico. Tanto em um quanto no outro, há uma dupla interpenetração do que é dito e do que não é dito, do paciente para o analista e do analista para o paciente. É necessário distinguir, portanto: a) o dito do paciente; b) o calado não dito e sabido do paciente; c) o calado não dito não sabido do paciente; d) o inaudível e o nunca ouvido do paciente; e) o dito do analista; f) o calado não dito e sabido do analista; g) o calado não dito não sabido do analista; e h) o inaudível e o nunca ouvido do analista (GREEN, 2004). Em todos estes casos, o silêncio se faz presente, pleno de significados e significações e portador de sentidos inconscientes e conscientes ${ }^{1}$.

Dito isso, a comunicação que se instala entre o par analítico liga os inconscientes e os corpos que ali dividem aquele espaço, trabalhando silenciosamente e retendo as palavras que não são pronunciadas, os sofrimentos que estão por vir, a dinâmica da transferência que se estabelece pouco a pouco, o sentido da confiabilidade e empatia que avançam como resultante desse encontro, e os sentimentos oriundos do analista a partir do que é vivido em conjunto com o seu paciente pela transferência e contratransferência. Às vezes, o tormento do não dito sacode o corpo e não chega à consciência do analisando (poderia, de igual modo, sacudir o corpo do analista, na medida em que ele intervém com sua palavra), fazendo com que o silêncio seja a mais perfeita tradução de uma alma em busca de sentido. Alma do analisando e corpo do analista; alma do analista e corpo do analisando são todas figuras que vão se constituindo e se delimitando na medida em que o processo terapêutico vai avançando.

Freud, como sabemos, foi um analista pouco afeito a investigar as origens do silêncio em seus pacientes. No início dos primeiros casos clínicos, ele os incitava a falar a partir da regra fundamental, e todo e qualquer silêncio produzido nos atendimentos era considerado uma dificuldade no caminho da psicanálise ou, dito de outro modo, um empecilho de se alcançar os conteúdos inconscientes. Com efeito, a regra de ouro da psicanálise nunca foi explicitamente anunciada por Freud, malgrado encontrarmos, em seus escritos técnicos e casos clínicos, indicações de como o médico vienense se comportava diante dos seus pacientes. Pelos seus próprios relatos e de seus herdeiros teóricos, sabemos que os analistas vienenses eram muito pouco silenciosos e passavam ao largo da neutralidade

${ }^{1}$ Para uma análise de outras configurações do silêncio na psicanálise, ver Gomes (2016a; 2016b; 2016c; 2015a; 2015b; 2014) e Gomes e Peixoto Júnior (2017). 
recomendada pelo mestre. Malgrado Freud nunca tivesse proposto uma metapsicologia para compreender os conteúdos que eram impedidos de serem verbalizados pelos seus pacientes, a incitação ao discurso era uma característica daquele grupo de analistas pioneiros, tal como veremos nas proposições metapsicológicas de Karl Abraham e retomada, nos anos 40, pelo psicanalista Robert Fliess, filho do amigo mais ilustre de Freud.

\section{ABRAHAM E A METAPSICOLOGIA DOS TIPOS LIBIDINAIS}

Karl Abraham foi um dos primeiros psicanalistas estrangeiros a fazer parte do pequeno círculo que se formou em torno de Freud às quartas-feiras, em Viena. Nascera em Bremen, uma das cidades da Liga Hanseática na Alemanha, em 1877, de família judia e extremamente religiosa. Era culto e resolveu cursar medicina, como era costume naquela época, terminando seu curso em Freiburg, próxima à fronteira da Suíça. Veio a se especializar em psiquiatria no hospital de Burghölzli de Zurique, onde conheceu Carl Gustav Jung, que o levou até Freud em 1907. Resolveu se mudar para Berlim, ali se instalando no ano seguinte e se tornando, dentre os estrangeiros que participavam do seleto Círculo de Viena, um dos principais personagens da psicanálise alemã. Abraham também fundou, juntamente com Magnus Hirschfeld, Ivan Bloch, Heinrich Körber e Otto Juliusburger, a Sociedade Psicanalítica de Berlim, da qual foi presidente até seus últimos dias, vindo a falecer prematuramente aos 48 anos (MEZAN, 2002; JONES, 1926/1970; ROUDINESCO; PLON, 1998).

Foi Abraham quem implantou a clínica freudiana no campo do saber psiquiátrico daquela época, transformando o tratamento das psicoses (esquizofrenia, psicose maníaco-depressiva, melancolia) a partir da psicanálise. Ele também elaborou uma teoria dos estágios da organização sexual, inspirada nas contribuições da sua aluna mais ilustre, a psicanalista Melanie Klein, formando outros psicanalistas dentre os quais Helene Deutsche, Edward Glover, Karen Horney, Sandor Rado e Ernst Simmel (ROUDINESCO; PLON, 1998).

De acordo com Mezan (2002), a postura do psicanalista alemão, que se tornou próximo de Freud, nunca foi a de contestar o mestre nem seus fundamentos teóricos, a exemplo de Reik e Ferenczi, e justamente por isso talvez tenha sido um pouco desprezado por Freud no que se refere às suas contribuições metapsicológicas. Para Jones (1926/1970), Abraham foi um autor prolífico durante sua vida como psicanalista, apresentando nada menos do que 46 comunicações nos 15 anos de presidência da sociedade psicanalítica que fundara, além da publicação de uma diversidade de artigos em várias áreas da psicanálise, sobretudo no que se refere ao papel da sexualidade e da libido na formação da personalidade e do caráter.

Seus estudos nessa área são decorrentes de quatro grandes textos de Freud: Três ensaios da teoria da sexualidade, Caráter e erotismo anal, As transformações do instinto exemplificadas no erotismo anal e Alguns tipos de caráter encontrados no trabalho psicanalítico (FREUD, 1905/1996; 1908/1996; 1916/1996; 1917/1996).

Em Três ensaios, como se sabe, Freud chama a atenção para as transgressões da anatomia com relação ao uso sexual da boca e das mucosas como zonas erógenas e lugares excitatórios onde se obtém prazer sexual. Faz do ato de chuchar um comportamento ligado ao autoerotismo e enfatiza os prazeres ligados à retenção e expulsão de fezes e urina na primeira infância. A excitação sexual na criança recebe importantes contribuições das excitações periféricas de determinadas partes do corpo - boca, ânus e uretra.

Em Caráter e erotismo anal, o desenvolvimento da personalidade será concebido a partir de três características de personalidade- um amor à ordem que muitas vezes se transforma em formalismo; a parcimônia que muitas vezes se transformará em avareza; e uma obstinação que pode se transformar em uma irada rebeldia- cada uma delas referida a um traço de caráter, decorrente da continência ou incontinência na retenção das fezes e urina. $O$ caráter de cada um de nós seria determinado pela fixação em uma das fases do desenvolvimento da libido e pelo modo como atravessaríamos essas fases. Haveria, portanto, um erotismo oral, uretral e anal que determinaria alguns tipos de caráter².

${ }^{2}$ Ferenczi (1930/1992) já havia pontuado algumas possibilidades de tratamento psicanalítico do caráter, apesar de não tratar dos tipos de caráter ao modo como Abraham ou Freud o fizeram. Pelo contrário, o analista húngaro vai 
Abraham não vai analisar o silêncio, a exemplo de Ferenczi (1916-17/1992), mas ampliará a concepção de determinados tipos de caráter a partir das proposições de Freud. Com isso, podemos pinçar, no escopo do seu trabalho, uma teoria para a compreensão do silêncio a partir desses tipos de caráter.

Sabemos ainda que ele deu pouca ênfase ao fenômeno da transferência. Porém, ressaltou a capacidade de transferência da libido para as pessoas de sexo oposto, para seres humanos em geral e para objetos em particular. A transferência é sustentada, assim, pela posição libidinal do sujeito na vida psíquica e é neste sentido que o silêncio do paciente vai ser revelado a partir da sua posição libidinal, na medida em que ele aparece como uma defesa contra os desejos erótico-orais (PELLEGRINO, 1988).

Em 1921, Abraham publicou Contribuições à teoria do caráter anal, quinze anos depois da primeira publicação de Freud sobre o assunto. Neste texto, ele analisa as contribuições do caráter anal na formação de determinados traços caracterológicos.

Retomando esses traços em Freud, Abraham afirma que o prazer primário em esvaziar os intestinos poderia ser sublimado no prazer de pintar, modelar ou em atividades similares, ou então avançava ao longo de um caminho de formação reativa, tal como um amor especial pela limpeza. Em outra perspectiva, retoma a relação indireta e inconsciente entre fezes e dinheiro, tal como no desenvolvimento de personalidades avarentas. Toda a relação será tomada a partir da forma como a criança lida com os seus excrementos e da forma como os adultos manejam ou educam seus filhos no trato com a limpeza intestinal (ABRAHAM, 1921/1927).

Muitos adultos não têm consciência do quão prazeroso é para as crianças entrar em contato com algo que sai de dentro delas. A preocupação dos pais com o cuidado e a limpeza de seus filhos, às vezes exagerada, leva a uma sobredeterminação na limpeza das partes excretoras, tal como descrito pelo autor:

O método primitivo de evacuação da criança coloca toda a superfície de suas nádegas e extremidades inferiores em contato com urina e fezes. Este contato parece desagradável e mesmo repulsivo para os adultos, cujas repressões os afastaram da reação infantil a esses processos. Eles não podem apreciar as fontes de prazer que a libido do bebê pode obter, quando o jato de urina morna sobre a pele e o contato com a massa tépida das fezes produzem sensações agradáveis. A criança só começa a dar sinais de desconforto quando os produtos excretados começam a esfriar sobre o seu corpo. (ABRAHAM, 1921/1927a, p. 372).

Ainda de acordo com Abraham, o prazer no ato da excreção compreende, além das sensações físicas, uma satisfação psíquica que se acha baseada na realização desse ato.

Exigindo uma estrita regularidade em suas excreções, bem como limpeza, o treinamento da criança expõe o narcisismo dela a um primeiro e severo teste. A maioria das crianças adapta-se mais cedo ou mais tarde a essas exigências. Nos casos favoráveis, a criança consegue transformar a necessidade em uma virtude, por assim dizer; noutras palavras, identifica-se com as exigências de seus educadores e fica orgulhosa de sua realização. (ABRAHAM, 1921/1927, p. 373).

As crianças, tão logo são educadas a conter ou expulsar seus excrementos em lugares específicos, aprendem que o que elas produzem pode ter um grande valor para seus pais. Passam a se guiar por esse modelo de retenção e expulsão como que para ganhar um elogio, uma recompensa ou um carinho dos pais. No entanto, se algum dano for causado por eles ao narcisismo infantil, especialmente se esses danos forem de natureza persistente e sistemática, diz Abraham, forçando o hábito da criança antes que esta esteja preparada, ela passará a transferir para os objetos (pai ou mãe, inicialmente) os sentimentos que originalmente se acham ligados ao seu narcisismo. Quando a criança adquire essa capacidade de transferir para os objetos os sentimentos ligados aos seus hábitos de limpeza, ela se torna limpa "pelo amor dessa pessoa". No entanto, se o hábito da limpeza for exigido muito cedo, ele poderá ser adquirido por meio do medo, fazendo com que sua resistência persista. Deste modo, a libido se fixará narcisicamente, resultando numa permanente dificuldade na capacidade de amar.

centrar na confiança o trabalho tanto com pessoas doentes de caráter quanto com pessoas com traços obsessivos ou histéricos. 
As crianças que crescem em um intenso ambiente anal-erótico incorporam no conjunto de suas lembranças um signo de enorme poder. Elas lidam o tempo todo com atitudes jocosas no que se refere ao trato intestinal e à forma como a educação e a limpeza são tratadas pelos adultos, superestimando a defecação e os excrementos por meio da linguagem corrente. Ao reconhecer no orgulho infantil pela evacuação um sentimento primitivo de poder, diz Abraham, é possível entender, por exemplo, a sensação de impotência encontrada em pacientes que se queixam de prisão de ventre neurótica, posto que sua libido fora deslocada da zona genital para a zona anal, inibindo suas funções intestinais do mesmo modo como se fosse uma impotência genital - é o caso das pessoas hipocondríacas que falam da sua impotência intestinal (ABRAHAM, 1921/1927a).

Geralmente, a prisão de ventre se apresenta nas crianças quando a defecação lhes é exigida, mas se rendem às necessidades quando a ocasião Ihes parece agradável. Sua dificuldade em evacuar na verdade nada mais é do que uma proteção contra os imperativos de reter ou expulsar os excrementos. As crianças aprendem, assim, o valor da dádiva, tal como formulado por Freud (1917/1996). Para Freud, desde muito cedo a criança valoriza as suas fezes, pois elas constituem algo que pode ser retido para ser preciosamente doado ao outro.

Uma vez que as fezes são a sua primeira dádiva, a criança transfere facilmente seu interesse dessa substância para uma nova, com que se depara, como a mais valiosa dádiva da vida. Aqueles que questionam essa derivação das dádivas deveriam considerar sua experiência de tratamento psicanalítico, estudar as dádivas que, como médicos, recebem dos pacientes e observar os tumultos de transferência que uma dádiva deles pode provocar nos pacientes. (FREUD, 1917/1996, p. 139).

Para Freud, o interesse pelas fezes ou pela urina continuava como parte do desejo da criança, deslocado para o dinheiro, por meio do impulso anal-erótico e de um impulso genital. Para o metapsicólogo, o pênis e a vagina têm uma relação com o impulso anal-erótico: a massa fecal representa-se como o primeiro pênis simbólico que a criança pode conceber, assim como a membrana da mucosa do reto pode representar a vagina. Todos eles podem mais tarde levar a traços de caráter obsessivo, caso venham a permanecer fixos nessa fase do desenvolvimento libidinal.

Abraham pensa na direção de Freud. Para ele, a entrega dos excrementos é a forma mais primitiva de uma criança doar ou presentear alguém. A relação com o dinheiro, neste caso, é direta. Reter ou doar fezes pode simbolizar guardar ou gastar dinheiro, guardar ou desperdiçar comida ou ainda reter a fala ou agir verborragicamente. Aqui encontramos a primeira formulação mais próxima de uma metapsicologia do silêncio a partir das contribuições de Abraham. O silêncio é a forma simbólica que o neurótico aprendeu ao guardar as palavras, porque elas valem tanto quanto um dia valeram seus excrementos. Em análise, elas só podem ser doadas para alguém que as mereça. Essa dinâmica econômica da libido se expressa na clínica por meio das palavras que compõem as associações livres, conforme descreve o autor:

Há certos neuróticos que evitam tomar qualquer espécie de iniciativa. Na vida comum, desejam um pai bondoso ou uma mãe atenta que estejam continuamente à mão para afastar todas as dificuldades de seu caminho. Na psicanálise, ressentem-se de ter de fornecer associações livres. Gostariam de ficar inteiramente quietos e deixar o médico efetuar todo o trabalho analítico ou, então, de serem interrogados por ele. A similaridade dos fatos revelados pela análise desses casos permite-me afirmar que esses pacientes, na infância, costumavam resistir ao ato de defecação, deles exigido, e que então se costumava poupar-lhes esse trabalho pela aplicação de frequentes enemas ou purgantes, por parte da mãe ou de seu pai. Para eles, a associação livre é uma evacuação psíquica e, tal como ocorre com a evacuação corporal, não gostam que se lhes peça que a efetuem. Estão continuamente à espera de que o trabalho lhes seja tornado mais leve ou seja completamente feito para eles [grifo nosso] (ABRAHAM, 1921/1927, p. 378-379).

Como pode ser observado, esse tipo de resistência está localizado nas fontes anais eróticas e refere-se à dificuldade dos pacientes em associar livremente, a despeito da atitude positiva do analista quanto à regra fundamental da psicanálise. Para exemplificar, o autor traz um estudo de caso com um de seus pacientes, que estava impedido de finalizar um trabalho acadêmico devido a uma resistência de longa data. Segundo o paciente, a sua dificuldade era a de iniciar o trabalho, posto que, uma vez iniciado, não poderia abandoná-lo de novo, situação que indica um caso exemplar de neurose obsessiva. 
Para Abraham, o exemplo dado refere-se ao comportamento dos neuróticos com relação às suas excreções, pois, ao reter os conteúdos no intestino ou na bexiga tanto quando podem, finalmente cedem às necessidades da natureza biológica evacuando todo o material retido. Neste mesmo paciente, também foi observada uma particularidade no que se refere ao erotismo anal: durante o tempo em que esteve em análise, ele permanecia inteiramente inativo por longos períodos de tempo, e, por meio dessa resistência, impedia que se produzisse qualquer alteração em seu estado. Seu único modo de lidar com as forças externas era praguejar violentamente, ao invés de pensar no êxito do seu trabalho, maldizendo-se pelas dificuldades que poderia enfrentar diante de suas injunções de insucesso. Por fim, sua atividade intelectual era substituída por um remoer neurótico. Suas associações faltavam e, quando vinham, eram sempre referidas ao cheiro e ao ruído produzidos por episódios de flatulência (ABRAHAM, 1921/1927).

Nessa perspectiva, a fala do paciente se assemelhava ao modo como lidava com o conteúdo intestinal: retendo as suas associações livres, ele produzia uma verdadeira congestão de pensamentos, insuportável de manter por muito tempo. Quando "a natureza" fazia o seu papel, descarregava a corrente de pensamentos retidos em palavras ao mesmo tempo em que produzia um relaxamento do esfíncter anal. Diante da possibilidade de produzir fezes, devolvia flatulência e passava a falar sobre esse episódio, demonstrando, portanto, a influência do erotismo anal tanto na formação do caráter quanto no tipo de discurso produzido em análise.

Além da influência do erotismo anal na formação do caráter, outro traço marcante é a influência do erotismo oral pontuado por Abraham (1924/1927). Mais uma vez, retomando Freud, explica que certos elementos do erotismo anal sofrem uma transformação e entram na organização final da vida sexual madura de todos os indivíduos; uma outra parte é sublimada e a terceira vai formar o caráter de todos nós. No entanto, o autor acredita que o erotismo oral também é fonte da formação do caráter, de modo análogo ao erotismo genital, o que indica que todas as zonas erógenas participam da formação do caráter.

Haveria duas características que distinguiriam o erotismo anal do erotismo oral. No que se refere ao primeiro, diz o autor, apenas uma parte das tendências prazerosas que se acham relacionadas com os processos intestinais podem vir a fazer parte do erotismo normal sob forma não reprimida, enquanto que outra parte bem maior dos investimentos libidinais da boca pode ser empregada na vida posterior, não havendo necessidade dos elementos orais da sexualidade infantil se transformarem em formação de caráter. No que se refere à segunda, diz Abraham, devemos ter em mente a existência de uma transformação regressiva do caráter na fase anal que vai, mais à frente, irromper em traços caracterológicos ou perturbações nervosas de diversas ordens (ABRAHAM, 1924/1927b).

Com isso, o autor quer afirmar que há uma relação muito próxima entre a origem do caráter oral e a história do erotismo oral. Enquanto que, na fase sádico-anal, existe um prazer ligado à retenção e expulsão das fezes, na fase sádico-oral o indivíduo tem um intenso prazer no ato de sugar e morder, independentemente da ingestão ou não de alimentos, posto que a boca se coaduna desde os momentos seguintes ao nascimento com uma zona erógena com vistas à obtenção de prazer. Esta forma primitiva de obtenção de prazer, diz Abraham, nunca é abandonada pelo indivíduo, e persiste sob todas as formas de disfarce ao longo da vida, podendo até experimentar algum tipo de reforço (é o caso, por exemplo, de pessoas que desenvolvem uma compulsão alimentar, permanecem todo o tempo mastigando algo ou precisam estimular a área da boca, com balas, bebidas ou cigarro, além de encontrar grande satisfação erótica na prática do sexo oral ou, por fim, no hábito da verborragia).

À medida que crescem, sabemos que as crianças renunciam ao seu prazer de sugar ou chuchar, deslocando-o para outras formas de obtenção de prazer, tais como as mencionadas acima. Além disso, há a irrupção dos dentes, na qual o prazer de sugar é substituído pelo prazer de morder. Este é o momento em que a criança começa a ter relações ambivalentes com os objetos externos, relacionando-se de forma tanto amistosa quanto hostil com eles. Nesse momento, diz Abraham, ocorre um outro deslocamento de sensações agradáveis para outras áreas e funções corporais, ou seja, o prazer em sugar ou morder sofre uma espécie de migração por volta da época em que a criança está sendo desmamada ou, dito de outro modo, quando ela passa a ser treinada nos hábitos de higiene e limpeza quanto a urina e fezes. 
Um importante requisito essencial para o sucesso deste último processo reside na função, em desenvolvimento gradual, dos esfíncteres anal e uretral. A ação destes músculos é a mesma que a dos lábios no sugar e, evidentemente, modelada sobre esta. A evacuação original, sem controle, das excreções corporais achava-se acompanhada por uma estimulação das aberturas do corpo que era indubitavelmente agradável. Se a criança se adapta às exigências do treinamento e aprende a reter suas excreções, esta nova atividade também vem a ser acompanhada de prazer. (ABRAHAM, 1924/1927, p. 396).

A principal questão que o metapsicólogo levanta é a fixação em uma dessas fases. Sabemos que há mães que são indulgentes com a limpeza de seus filhos, muito embora haja outras que levem a maternidade a sério e tenham grande habilidade em repassar para eles os tratos com a higiene e a limpeza. A mãe tem que ser habilidosa para conseguir desmamar o seu filho na hora certa sem que a criança experimente esse momento como uma dificuldade, vindo a se aferrar com intensidade aos prazeres obtidos nesse estágio do erotismo oral. Caso isso ocorra, haverá a possibilidade do desenvolvimento de traços de caráter onde se dará não só uma fixação como também uma regressão a esse estágio do desenvolvimento.

Noutras palavras: na criança que foi desapontada ou excessivamente gratificada no período da sucção, o prazer em morder, que é também a forma mais primitiva de sadismo, receberá ênfase especial. Dessa maneira, a formação do caráter em tal criança começa sob a influência de uma ambivalência de sentimento anormalmente pronunciada. (ABRAHAM, 1924/1927b, p. 398).

Uma vez ocorrida a fixação nesta fase, não raro podemos depreender dois tipos de manifestações clínicas: ou pacientes que não se contêm nas palavras e falam a expensas da corrente de pensamentos, quase que obtendo prazer neste hábito; ou pacientes que são comedidos nas palavras, posto que nunca puderam desenvolver sua oralidade em decorrência da inabilidade de seus pais no devido cuidado durante a fase de amamentação, desmame ou experiências autoeróticas, tais como o chuchar.

Todo o caráter de uma pessoa se acha sob influência do erotismo oral, mas só podemos demonstrar isso caso a caso. Ao atravessar o estágio oral, podemos encontrar pessoas que podem experimentá-lo de modo prazeroso ou desprazeroso, satisfatório ou perturbado. Os traços característicos de sujeitos que atravessaram esse período de modo desprazeroso ou perturbado são justificados pelo caráter social em que essas pessoas parecem solicitar algo das outras. São uma espécie de "vampiros" sugadores que se aferram às pessoas, detestam ficar sozinhas, mesmo que por pouco tempo; sua impaciência é uma peculiaridade da sua personalidade e uma investigação psicanalítica revela, no mais das vezes, uma regressão do estágio sádico-oral para o de suç̧ão. Consequentemente, seu anseio por experimentar gratificação por meio da sucção transformou-se, para Abraham, numa necessidade de "dar através da boca", ou seja, desejam conseguir tudo o que puderem para satisfazer seu desejo, ao passo que têm necessidade constante de se comunicar oralmente com outras pessoas, resultando em uma obstinada necessidade de falar, somada a uma hiperfluência verbal e comunicação exacerbada. Nestes casos, as pessoas têm a impressão de que sua reserva de pensamento é infindável, tratando tudo o que têm a dizer com um valor inestimável. Fazem uma verdadeira descarga oral por meio da fala (ABRAHAM, 1924/1927).

Ademais, nesse tipo de caráter, a fala toma o lugar dos impulsos reprimidos e, ao invés de morder e devorar o objeto, a conversa surge como forma de expressar toda a sua agressividade. $O$ desejo de falar, por assim dizer, significa tão somente o desejo de atacar, aniquilar e matar o seu adversário, em uma espécie de "evacuação corporal" pela fala. Para Abraham, em tais casos, o falar está sujeito à valorização narcísica de suas produções (físicas e psíquicas) no campo da fantasia.

Será a partir de todas essas considerações centradas no erotismo oral, anal, uretral e genital que Robert Fliess, filho do amigo íntimo e correspondente de Freud de mesmo sobrenome, construirá uma articulação com Abraham acerca do silêncio e da verbalização.

\section{SILÊNCIO E VERBALIZAÇÃO: A TIPOLOGIA CLÍNICA DE ROBERT FLIESS}

Citando Ella Freeman Sharpe, em seu texto Problemas psicofísicos revelados na linguagem, Robert Fliess 
estabelece de imediato uma conexão entre os poderes da verbalização e as relações excretórias do corpo, conforme se segue:

Quando o ego finalizou sua obra e o controle do corpo é equilibrado e automático, não podemos mais manejar da mesma maneira as emoções de cólera e prazer que até então acompanhavam as descargas corporais. A criança adquire ao mesmo tempo a linguagem e o controle esfincteriano do ânus e da uretra, e essa nova possibilidade de exterioridade, presente desde o nascimento, vai ser de primeira importância. A descarga da tensão, que não pode mais se efetuar pelo viés do físico, pode se dar pela palavra. A atividade de falar substitui a atividade das aberturas do corpo. As palavras tornam-se substitutos de substâncias corporais... [grifos do autor] (SHARPE, apud FLIESS, 1949/2010, p. 61).

Para Fliess, o que Ella Sharpe assinala é uma extensão do que Abraham já descrevera na segunda década do século passado, ou seja, que a libido liberada pela palavra é sempre "oral", enquanto que a erogeneidade em causa é sempre "uretral". Para algumas pessoas, falar pode ser substitutivo total ou parcial do ato urinário infantil sexual agressivo ou, nas palavras de Abraham, a necessidade de "dar pela boca". Poderíamos ir mais adiante no argumento de Abraham: para o autor, haveria uma valorização narcísica idêntica àquela produzida no inconsciente e que é atribuída às produções corporais e psíquicas por via das atividades excretórias; necessariamente, urina e fezes. Para Abraham, então, a necessidade de falar significa, ao mesmo tempo, desejar, atacar, matar ou destruir e, ao mesmo tempo, toda espécie de evacuações corporais, aqui inclusa a fecundação.

Assim, citando Abraham, diz Robert Fliess que "o tipo particular de excreção que os sujeitos imitam por meio do discurso é urinário, a descarga instintiva é erótico-uretral, e seu fim procriativo só pode ser compreendido sobre a base de uma persistência das teorias infantis e de uma organização fálica" (FLIESS, 1949/2010, p. 62).

Os tipos caracterológicos descritos por Abraham utilizam o aparelho da linguagem para realizar por deslocamentos uma "descarga pulsional regressiva erótico-uretral e tiram de suas palavras a mesma gratificação pulsional que obtinham e ainda obtêm na micção" (FLIESS, 1949/2010, p. 62). Todo o aparelho da linguagem, nessa matriz teórica, serve de objeto de descarga pulsional, imitando o ato fisiológico de sugar ou excretar, utilizando-se da zona erógena da boca ou dos esfíncteres anal e uretral, e condicionando a palavra de acordo com uma produção excretora particular.

Os sujeitos representados por esta matriz de descarga pulsional são descritos em três tipos: erótico-oral, erótico-uretral e erótico-anal. A linguagem, no cerne do discurso, será compreendida a partir de traços caracterológicos nos quais a palavra pode ser objeto de deslocamento de descarga pulsional das mesmas ordens dos tipos descritos acima. Para Fliess (1949/2010), o aparelho da linguagem funcionaria conforme o modelo das atividades erógenas de uma zona particular, tal como os traços de caráter descritos por Abraham. Esse modelo, diz o autor, condicionaria a palavra segundo um modo de produção excretora particular, havendo, portanto, três tipos de linguagem conforme os tipos libidinais: a linguagem erótico-uretral, a linguagem erótico-anal e a linguagem erótico-oral. Para cada uma dessas formas particulares de linguagem, o autor estabelece uma correspondência com um tipo de silêncio específico, posto que, se a palavra é um substituto da atividade esfincteriana, o silêncio equivaleria ao fechamento de um desses esfíncteres; e a dificuldade do analisando em seguir a regra fundamental da análise corresponderia a um medo de deslocamento dessa incontinência, ou, dito de outro modo, quando um paciente para de falar, a retenção das palavras pode corresponder a um tipo de produção excretora (FLIESS, 1949/2010).

De acordo com o autor, haveria então três tipos de silêncio, que corresponderiam a essa forma particular de fechamento esfincteriano(o silêncio erótico-uretral, o silêncio erótico-anal e o silêncio erótico-oral), cada um deles correspondendo ao conjunto de características a seguir: "a maneira pela qual começa a pausa no discurso; o grau e o tipo de oposição à palavra e à comunicação do pensamento pelo silêncio; o comportamento durante o período de silêncio; o cessar, ou seja, a reação do paciente à injunção do analista para que retome a fala" (FLIESS, ibidem, p. 64).

O silêncio erótico-uretral é a forma mais normal de silêncio e a que mais lembra a pontuação durante uma conversação. $O$ aparelho da linguagem funciona conforme o modelo do esfíncter uretral no momento do seu 
fechamento, e o paciente não parece paralisado diante de nenhum conflito, seja ele interno ou externo, no início ou fim de momentos de silêncio. O que se pode observar é que o paciente está construindo o seu pensamento diante da sua fala. Se interrompido o fluxo de suas palavras, o aparelho de linguagem funcionará segundo o esfíncter da uretra sem graves problemas quanto ao seu fechamento ou à sua abertura (FLIES, 1949).

O silêncio erótico-anal, ao contrário do seu correlato anterior, parece emanar de uma inibição. Durante o decurso de uma fala, o silêncio que se faz presente parece perturbar o falante, que não consegue prosseguir o fluxo de pensamentos quando convidado pelo analista, apresentando um estado de tensão e conflito. Tal qual a abertura e o fechamento do esfíncter anal, o paciente, quando experimenta momentos prolongados de silêncio, é capaz apenas de entregar uma pequena parte de seus pensamentos, o que torna esse tipo de silêncio mais regressivo do que o silêncio erótico-uretral, havendo ainda a possibilidade de apresentar uma "constipação verbal" quando manifesto.

Por fim, o silêncio erótico-oral é aquele que escapa ao controle da erogeneidade oral e, ao contrário dos anteriores, substitui uma verbalização pelo silêncio propriamente dito. Lembra muito o mutismo e dá a impressão de que o paciente se ausentou física e psiquicamente, dado que esse silêncio se mostra interminável e raramente cessa diante de um pedido do analista. Aqui, apresenta-se uma falta completa de afeto, de motivação, que pode induzir, sustentar ou acompanhar esse período de silêncio. De acordo com Fliess (1949/2010), em situações de silêncio erótico-oral, o paciente libera energias ativas e passivas, explorando a situação analítica em termos de uma transferência que exige a incorporação do sujeito e do objeto; portanto, o analista deixa de existir como objeto do mundo exterior, perdendo sua capacidade sugestiva. Neste tipo de silêncio, o aparelho de linguagem funciona a partir do controle do afeto regressivo de um ego infantil e precoce.

Para Fliess (1949), as diferentes formas de silêncio erótico parcial que se opõem à verbalização não passam de uma luta pelo controle da descarga pulsional engajada pelo ego infantil. Ao transformar os derivados do pensamento inconsciente recalcado em representações de palavras sonorizadas, a verbalização necessita de uma abertura do corpo que delimite uma zona erógena, permitindo uma regressão a essa zona. Sem o recurso à regra fundamental da psicanálise, essa descarga não seria possível. Logo, para diferentes tipos de personalidade ou traços de caráter, apresentar-se-ia um tipo de sintoma diferente, e, para cada um deles, o analista deveria ser cuidadoso ao abordar o silêncio manifesto no setting, pois, para cada caso, haveria uma forma diferencial no manejo da técnica.

\section{CONSIDERAÇÕES FINAIS}

Como vimos, ao longo desse trabalho, em termos econômicos e dinâmicos, a verbalização é o motor de diferentes modos de pensar e necessita de uma certa quantidade de energia para ser ab-reagida. De um ponto de vista topográfico, a verbalização é uma resposta à motilidade (discurso) e à percepção (pensamento) dos conteúdos vividos dentro do psiquismo do paciente, ou, dito de outro modo, a verbalização é tanto uma função do ego quanto um instrumento de apropriação dos conteúdos recalcados e inconscientes.

Como um autor mais clínico do que teórico, Abraham quer nos mostrar como os conteúdos vividos pelo paciente têm uma dupla função - ou de retenção ou de expulsão desses conteúdos vividos no psiquismo - e sua não elaboração pelo paciente durante seu processo de análise. Há, portanto, uma necessidade de elaboração desses conteúdos para que uma função de descarga "verbal", "anal" ou "uretral" seja vivida clinicamente pela dupla analisando-analista, uma vez que a verbalização e o tipo de erogeneidade reprimida vão formar um traço ou tipo de caráter.

Por fim, a tipologia clínica libidinal, na metapsicologia de Abraham, e sua redescrição por Robert Fliess, dos modos de compreender os diversos sentidos do silêncio vividos pelos pacientes no setting, podem se constituir em uma ferramenta clínica útil ao entender determinados traços de caráter e sintomas vividos pelos pacientes nos dias de hoje, a partir da relação entre erogeneidade e as diversas formas de silêncio e verbalização. Do mesmo modo, é preciso compreender que, quando o silêncio se manifesta numa sessão de análise, ele pode assumir uma diversidade de sentidos, necessitando de uma escuta profunda, por parte do analista, do sofrimento vivido pelo seu paciente. 


\section{$\underline{\text { Sergio Gomes }}$}

Sem essa escuta mais profunda do sujeito em análise, não haveria encontro com o outro sofredor, e, sem o encontro com o outro sofredor, "tudo quanto podemos é esperar que o paciente encontre por si mesmo a coragem de tornar possível o impossível. O resto é silêncio" (REIK, 1926/2010, p. 18).

Recebido em: 22 de agosto de 2016. Aprovado em: 29 de abril de 2017.

\section{REFERÊNCIAS}

ABRAHAM, K. Contributions to the theory of the anal character(1921). In: Selected papers of Karl Abraham. London: Hogarth Press, 1927.

.The influence of oral erotism on character-formation(1924). In: Selected papers of Karl Abraham.London: Hogarth Press, 1927.

BARANDE, R. Essai métapsychologique sur le silence: de l'objet total phallique dans la Clinique du silence. Revue Française de Psychanalyse, 28(1), 1963, p. 177-220.

FERENCZI, S. O silêncio é de ouro (1916-17). In. . Psicanálise II. São Paulo: Martins Fontes, 1992. (Obras completas).

. O tratamento psicanalítico do caráter (1930). In Psicanálise IV. São Paulo: Martins Fontes, 1992. (Obras completas).

FLIES, R. Silêncio e verbalização: um suplemento à teoria da "regra analítica" (1949). In NASIO, J.-D. (org.), $O$ silêncio na psicanálise. Rio de Janeiro: Zahar, 2010, p. 59-80.

FREUD, S. Além do princípio de prazer(1920).Rio de Janeiro: Imago, 1996. (Ed. standard brasileira das obras completas, 18).

. Alguns tipos de caráter encontrados no trabalho psicanalítico (1916). Rio de Janeiro: Imago, 1996. (Ed. standard brasileira das obras completas, 14).

As transformações do instinto exemplificados no erotismo anal (1917). Rio de Janeiro: Imago, 1996. (Ed. standard brasileira das obras completas, 17). completas, 9).

Caráter e erotismo anal (1908). Rio de Janeiro: Imago, 1996. (Ed. standard brasileira das obras

Três ensaios sobre a teoria da sexualidade (1905). Rio de Janeiro: Imago, 1996. (Ed. standard brasileira das obras completas, 7).

GOMES, S. A Gramática do Silêncio: um estudo sobre comunicação e a não comunicação na psicanálise. Tese de Doutorado. Programa de Pós-Graduação em Psicologia Clínica. Pontifícia Universidade Católica do Rio de Janeiro, 2014.

A linguagem dos gestos e dos corpos: o silêncio na perspectiva clínica de Sándor Ferenczi. Cadernos de Psicanálise (Círculo Psicanalítico do Rio de Janeiro), 37(32), 2015b, p. 197-122. $29-54$ Do feto ao bebê: Winnicott e as primeiras relações materno-infantis. Psicologia Clínica, 28, 2016a, p.

Eu vi que você viu que eu vi: a tríplice hélice narcísica no pensamento clínico de D. W. Winnicott Tempo Psicanalítico, 48(1), 2016b, p. 9-828.

Silêncio e segredo: sobre o desenvolvimento da capacidade de pensar. Estudos e Pesquisas em Psicologia, 16(4), 2016c, p. 1310-1333. $129-145$

Winnicott e Margaret Little: o manejo do silêncio em uma paciente difícil. Trieb, v. 14(1-2), 2015a, p.

GOMES, S.; PEITOXO JÚNIOR, C. PEIXOTO JUNIOR, C. A. A teoria da comunicação no pensamento clínico de Donald W. Winnicott. Cadernos de Psicanálise (Círculo Psicanalítico do Rio de Janeiro), 39(36), 2017, p. 63-85.

GREEN, A. O silêncio do psicanalista. Psychê, ano VIII, 14, 2004, p. 13-38.

JONES, E. Introdução (1926). In ABRAHAM, K. Teoria psicanalítica da libido: sobre o caráter e o desenvolvimento da libido. Rio de Janeiro: Imago, 1970, p. 1-31.

MEZAN, R. Interfaces da psicanálise. São Paulo: Cia das Letras, 2002.

PELLEGRINO, M. C. Silêncio, silêncios. In: BIRMAN,J. (org.). Percursos na história da psicanálise. Rio de Janeiro: Taurus, 1998, p. 175-198

REIK, T. No início é o silêncio (1926). In: NASIO, J.-D. (org.).O silêncio na psicanálise. Rio de Janeiro: Zahar, 2010,p. 17-23.

ROUDINESCO, E.; PLON, M. Dicionário de psicanálise. Rio de Janeiro: Zahar, 1997.

\section{Sergio Gomes}

sergiogsilva@uol.com.br 